\title{
Construction Design and Sustainability in Architecture
}

\section{Bada A.O ${ }^{\ngtr}$ \\ Akharia O.O ${ }^{2}$ \\ Daodu, S.A ${ }^{2}$ \\ Dania, S.F}

'Department of Urban $\S^{\circ}$ Regional Planning, Auchi Polytechnic, Auchi, Nigeria.

'Email:afolabibada@yahoo.com Tel: +2348038885232

${ }_{2,3}$ Department of Architectural Technology, Auchi Polytechnic, Auchi, Nigeria.

EEmail:omoyeakharia@yahoo.com Tel:2348023359572

Email.fredomafredi2000@vahoo.com Tel.+284803849647s

${ }^{4}$ Department of Building Technology, Auchi Polytechnic, Auchi, Nigeria.

${ }^{*}$ Email:sunny4alldanias@yahoo.com Tel:23408066308438

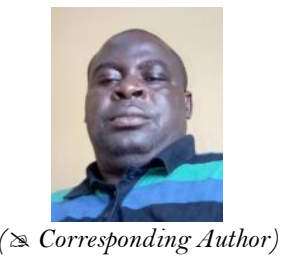

\begin{abstract}
The study aims to access the implementation of sustainable housing indicators (SHI) in the building design and construction in Ondo State, Nigeria. Generally, the overall degree of incorporating SHI in the building construction showed that Ondo Central District (OCAEZ) has the highest design compliance, while the awareness is unpopular in Ondo North District (ONAEZ) and Ondo South District (OSAEZ). Conversely, the selection of sustainability key indicators is very important at the early design stage and this would be veritable to projecting the environmental impact, energy and air quality sustainability potency of building. This development will go a long way to integrate and improve the building design and construction and enabling sustainability in building development.
\end{abstract}

Keywords: Sustainable housing indicator, Environmental impact, Sustainability, Building design, Ondo State.

Citation | Bada A.O; Akharia O.O; Daodu, S.A; Dania, S.F (2020). Construction Design and Sustainability in Architecture. Asian Review of Environmental and Earth Sciences, 7(1): 41-46. History:

Received: 19 December 2019

Revised: 24 January 2020

Accepted: 27 February 2020

Published: 6 April 2020

Licensed: This work is licensed under a Creative Commons Attribution 3.0 License (oc) By

Publisher: Asian Online Journal Publishing Group
Acknowledgement: All authors contributed to the conception and design of

the study.
Funding: This study received no specific financial support.

Competing Interests: The authors declare that they have no conflict of Competing
interests.

Transparency: The authors confirm that the manuscript is an honest, accurate, and transparent account of the study was reported; that no vital features of the study have been omitted; and that any discrepancies from the study as planned have been explained.

Ethical: This study follows all ethical practices during writing.

\section{Contents}

1. Introduction

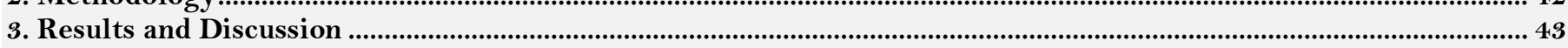

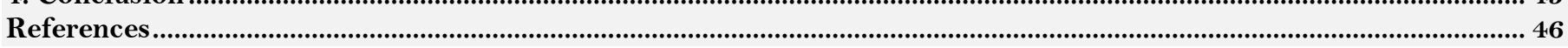




\section{Contribution of this paper to the literature}

The study contributes to existing literature by accessing the implementation of sustainable housing indicators (SHI) in the building design and construction in Ondo State, Nigeria.

\section{Introduction}

Sustainable building design and construction is the practice of making structures and using processes that are environmentally responsible and resource efficient throughout the life cycle of a building from selecting the site to design, construction, operation, maintenance, renovation, and finally, deconstruction. The building industry is a vital element of any economy but has a significant impact on the environment [1]. Sustainability is an important issue to consider in building design, for environmental design and socio-economic to integrate and develop global architectural excellence. Until modern architecture conquered the world, architecture was mostly rational, functional, hence resource conserving and energy saving in the regional/local climatic context [2]. Architecture exemplified the local physical appearance or a place. Akadiri, et al. [1] reported that vernacular architecture, by its nature, had built-in sustainability, both physical and cultural. Several important variables and indicators are considered at the onset of design phase for building analysis and sustainability projections. Studies of many authors have agreed on the significance of indicators to measure and predict sustainability in architecture. The concept of sustainability includes promoting the quality of life, thus allowing people to live in a healthy environment, with improved social, economic and environmental conditions [3].

Sustainable buildings should be designed and developed to take in cognizance factor to limit and mitigate greenhouse gases emission (GHG), environmental pollution such as noise, and integration of indoor and outdoor air quality and cross ventilation. John, et al. [4] reported that a number of certain objectives such as resource and energy efficiency, $\mathrm{CO}_{2}$ and $\mathrm{GHG}$ emissions reduction, pollution prevention, mitigation of noise, improved indoor air quality, harmonization with the environment should be considered in building design for optimal sustainability. Many studies have revealed that that the world population will increase by more than $45 \%$ by the mid of $21^{\text {th }}$ century. The projected increase in population could be a major factor for exponential demand for shelter and housing units mostly in developing countries. The pressure of creating a sustainable housing unit for the increasing population will further complicate the environmental processes through the deforestation, consumption of huge fossil fuel and depletion of ozone layer from the building production companies. Globally, the building sector is arguably one of the most resource-intensive industries [1].

A sustainable housing design involves highly simulated and technically-based approaches which allows continuous modifications and adjustment at every stage. Ensuring the high quality of design is to ensure an approach based on building performance, an integrated and interdisciplinary project team working through an integrated planning and preparing a project to its best performance [5]. Thus, the design process is crucial because most decisions that will determine building performance in use will be made at this stage [5]. In any architectural project, the principal intention and objective of the project has to be clearly defined. The conceptual ideal must be well studied, queried and modified to meet the expected client's demand. During this initial phase, clients and design team share information seeking to develop the building's concept. The architectural programming is required to define key requirements and constraints towards project quality.

The study aims to measure and identify the sustainability indicators in housing design and to determine its adaptability to the architectural design and construction in Ondo State, Nigeria. The output of this study is aimed to allow the architect and other housing designers to accommodate environmental sustainability indicators in their housing design from the early to completion stage at affordable cost.

\section{Methodology}

Housing design and development today is much different from what used to be obtainable many decades ago; these changes are mostly in the cities, developing and developed environment. However, improvement is incorporated to make housing facility be more conducive to enhance healthy living and socio-economic activities. The advancement in housing design includes introduction of integrated mechanism which could be used to mitigate the emission of GHGs, air-quality monitor and automated ventilators. To make building to be sustainable, allowance for all integrated indicators must be provided. Modern movement and modernism have made a huge impact on industrial buildings, while at the same time industry has influenced the modernistic architects [Q]. In order to achieve a sustainable future in the building industry, Asif, et al. [6] suggest adoption of multi-disciplinary approach covering a number of features such as: energy saving, improved use of materials, material waste minimization, pollution and the greenhouse gas emissions control measure etc. Having considered the importance of designing for sustainable use, a set of design-indicator data was obtained in Ondo State, Nigeria for this study. The sustainable housing (SHI) indicators considered are as follows:

i. Environmental impacts include global warning, depletion of ozone layer, $\mathrm{CO}_{2}$ and climatic monitors (EI).

ii. $\operatorname{Energy}(\mathrm{E})$.

iii. Life cycle cost (LCC).

iv. Air quality control (AGC).

Ondo State has a total landmass area of $77,818 \mathrm{Km}^{2}$ located in Southwestern Nigeria. The study area is surrounded by the states of Kwara and Kogi on the north, Edo on the east, Delta on the southeast, and Osun and Ogun on the west and by the Bight of Benin of the Atlantic Ocean on the south. The study area comprises mangrove-swamp forest near the Bight of Benin, a tropical rain forest in the centre part, and wooded savannah in the north. Ondo State is located at an elevation of 264 meters above sea level and lies on coordinates $7^{\circ} 10^{\prime} \mathrm{O}^{\prime \prime} \mathrm{N}$ and $5^{\circ} 4^{\prime} 60^{\prime \prime}$ E in DMS (Degrees Minutes Seconds). Figure 1 shows the location of Southwestern region and Ondo State inside the map of Nigeria. Construction of housing units and other infrastructural amenities are on-going in the State to meeting the growing population. Many building designers have been preoccupied with style and formmaking, disregarding environmental quality and human satisfaction in and around the built environment [1]. Conversely, design to promote and protect human health and well-being should be the priority of architect and other designers. The sustainable housing (SHI) indicators were measured from three categorized regions (Ondo 
Central Agro-Ecological Zone in the State [ONAEZ], Ondo South Agro-Ecological Zone [OSAEZ] and Ondo Central Agro-Ecological Zone [OCAEZ]) that made up of Ondo State.

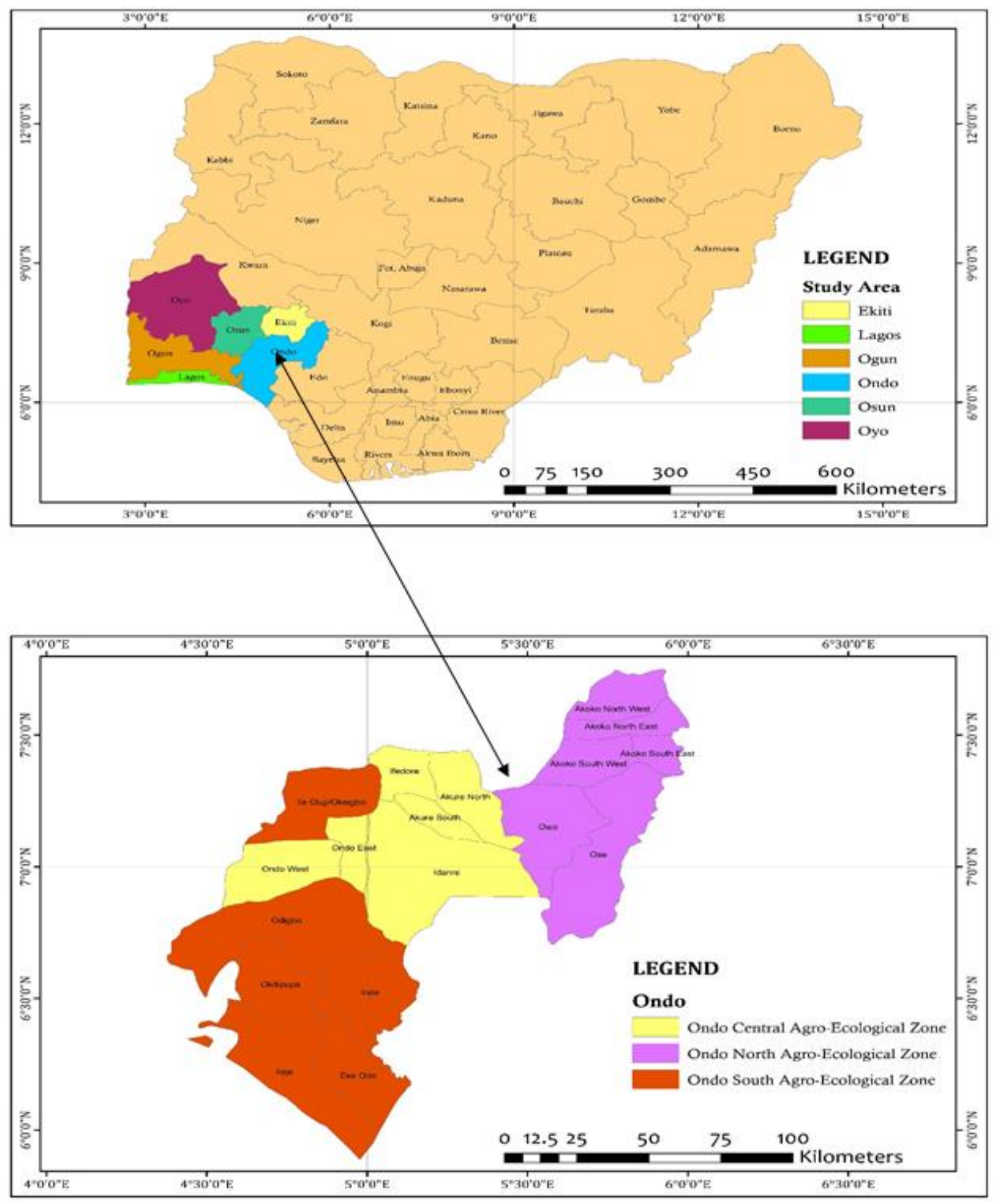

Source: ODSMA [7]

\section{Results and Discussion}

Table 1 shows the results of selected Sustainable Housing Indicator (SHI) in every ecological zone of the State. In Ondo Central Zone (OCAEZ), it clearly shown that there exists a great awareness of incorporation of SHI into the building designs. Environmental impact indicator (Global warning, depletion of ozone layer, $\mathrm{CO}_{2}$ and climatic monitors).

Table-1. level of sustainable housing indicator design.

\begin{tabular}{c|c|c|c|c}
\hline & \multicolumn{4}{|c}{ Sustainable Housing Indicator (\%) } \\
\hline Study region & EI & E & LCC & AGC \\
\hline ONAEZ & 20.3 & 20.6 & 46.2 & 43.4 \\
\hline OCAEZ & 38.4 & 55.4 & 61.5 & 66.2 \\
\hline OSAEZ & 15.2 & 13.2 & 10.8 & 15.2 \\
\hline Source: Field output, 2019
\end{tabular}

Source: Field output, 2019.

\subsection{Air Quality Control}

Indoor air quality (IAQ) is the air quality that flows within and around building and structures. It has been a reality that IAQ affects the health and well-being of the people occupying the building. Poor indoor air quality has been associated with a number of ailments and diseases such as depression, suffocation, headache, assimilation and concentration problems. Bruce, et al. [8] reported that indoor air quality could be affected by gases such as carbon 
monoxide, radon, volatile organic compounds, particulates, microbial contaminants or any mass or energy stressor that can induce adverse health conditions. In view of this, incorporation of air quality control and monitor becomes a necessity in modern housing design. The result in Table 1 shows that $43.4 \%$ and $15.2 \%$ of the sampled modern houses in Ondo north District (ONAEZ) and Ondo South District (OSAEZ). However, Ondo Central District (OCAEZ) indicated the highest building structures of $66.2 \%$ as showed in Figure 2. This observation shows there is a growing awareness to upgrade the quality of indoor air quality in the State. Urbanization, class, status and education are the major factors that actually influence the installation of air quality monitors in most houses. Ondo Central District of the State comprises the most educated people and also houses the capital town of the State as such, the awareness in this region is extremely high. The observation from this findings, it is revealed that the people dwelling in OCAEZ) enjoyed better health status than the dweller from the less developed districts (ONAEZ and OSAEZ) which could be related to improved quality of air. Indoor air pollution in developing nations is a major health hazard [9]. A major source of indoor air pollution in developing countries is the burning of biomass (e.g. wood, charcoal, dung, or crop residue) for heating and cooking [9].

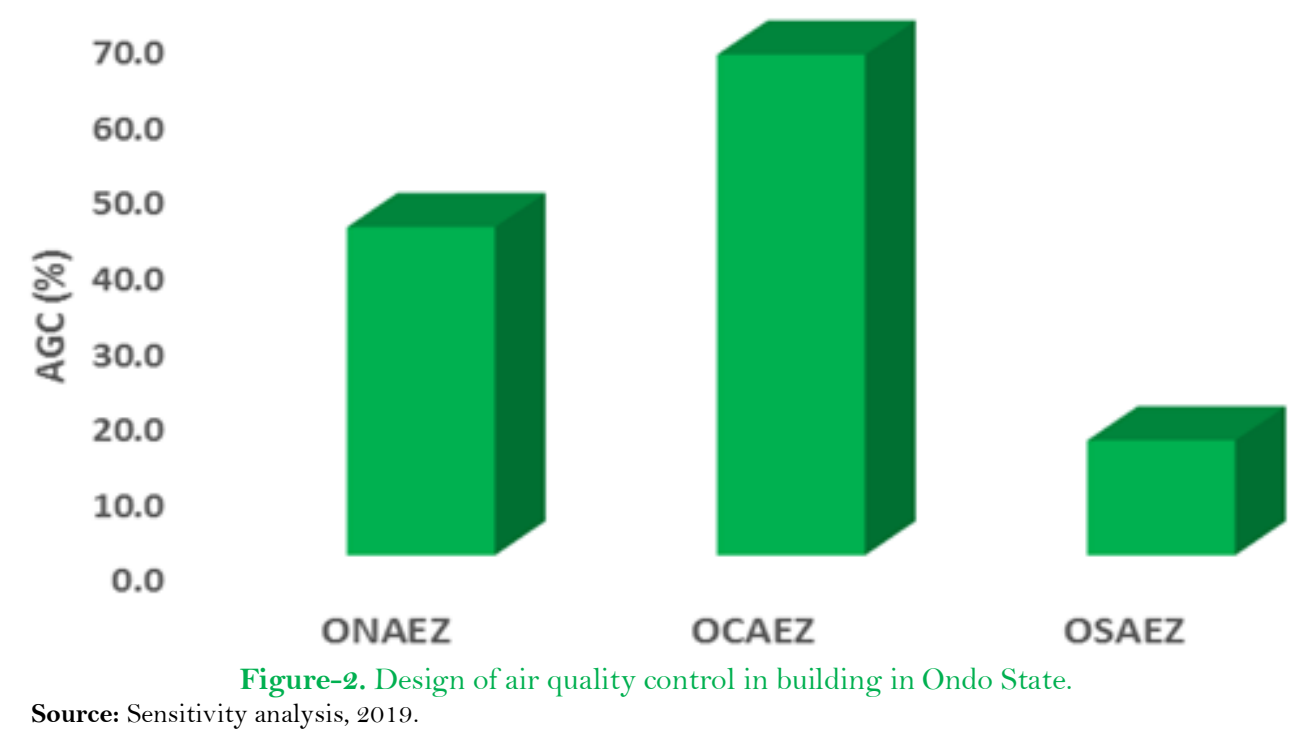

\subsection{Life Cycle Cost}

Life cycle cost is a method of economic analysis directed at all costs related to constructing, operating, and maintaining a construction project over a defined period of time. The main question for a sustainable design is how to put economic optimization into the early design stages. Early stages of the design processes are very critical phases to take a decision related to critical issues which are construction and operating costs, Bogenstätter [10] stated that ecological and economic objectives perfectly complement each other to achieve sustainability. The result in Table 1 and Figure 3 shows that the Ondo Central District (OCAEZ) has the highest design for LCC in the early stages of building constructions, whereas there is a poor awareness of LCC in Ondo South District (OSAEZ). Also, there is a growing of incorporating LCC design in building structures at Ondo North District (ONAEZ). Pellegrini-Masini, et al. [11] investigate the total lifetime costs of three cases of energy demand reduction technologies over a 25 years' period (2005-2030) for housing stock in the UK. Woodward [12] study life cycle costing to evaluate housing affordability with the aid of a computer program. Woodward [12] draw attention to the significance of energy consumption in affordable houses.

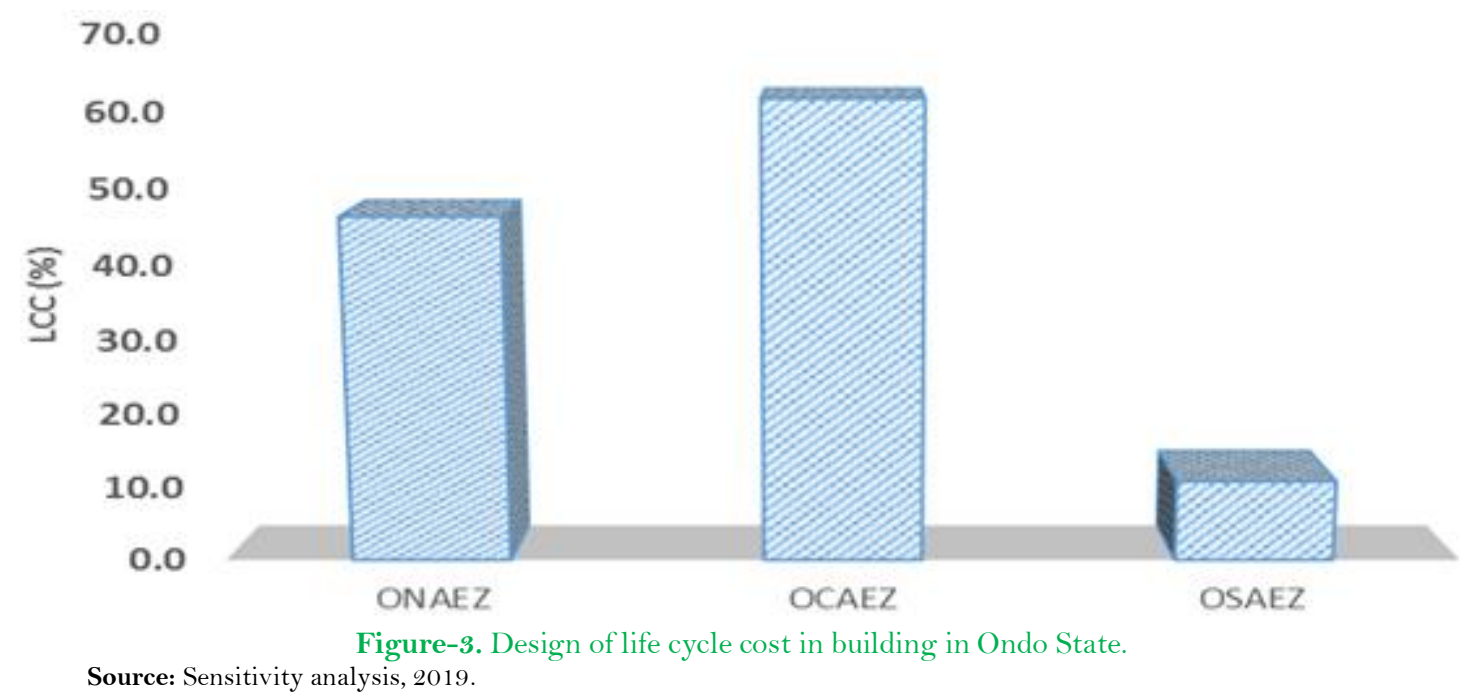




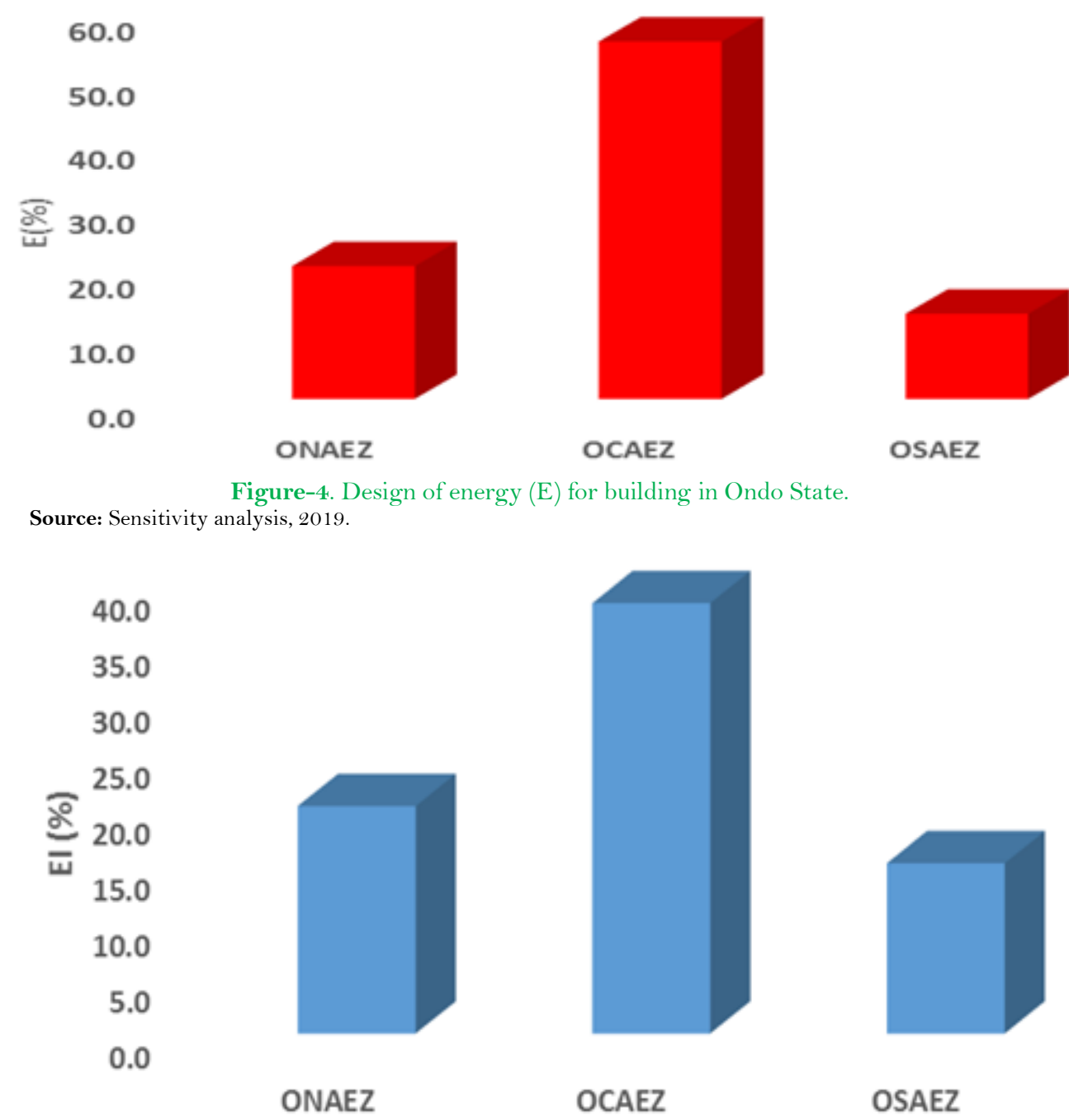

Figure-5. Design of environmental impacts (EI) for building in Ondo State. Source: Sensitivity analysis, 2019 .

\subsection{Energy}

Buildings consume energy and other resources at each stage of building project from design and construction through operation and final demolition [3]. Building construction consumes large volume of energy throughout the construction stages. According to Lenzen and Treloar [13] reported that the kind and amount of energy use during the life cycle of a building material, right from the production process to handling of building materials after its end life can, for example, affect the flow of greenhouse gases (GHGs) to the atmosphere in different ways over different periods of time. Based on this, it is important to reduce the energy used mostly through the burning of fossil fuel and exploit the renewable energy mix. For that reason, the total demand for primary energy should be minimized and the share of renewable energy should be maximized while reducing the share of nonrenewable energy during the building's life cycle [5]. It is clearly revealed that the energy (E) consumption for the Ondo Central District (OCAEZ) is the highest in the region with $54.4 \%$ whereas in Ondo North District (ONAEZ) and Ondo South District (OSAEZ) have less consumptive rates of $20.6 \%$ and $13.2 \%$ Table 1 and Figure 4 . The output of the energy analysis showed that the rate of urbanization is a critical factor that influence energy used in the building design and construction. However, most of the buildings in the urban centres have design provisions for space heating, space cooling, domestic hot water production and other energy consuming appliances.

\subsection{Environmental Impacts}

The building life cycle is an approach to design that considers environmental impacts such as pollution, energy consumption, global warming potential-GWP, greenhouse house emission over the life of the building. These environmental impact factor could also be determined using SimaPro standard of impact estimator software. However, it is showed that the environmental impact is lowest at Ondo South District (OSAEZ) with $15.2 \%$ and highest at OCAEZ as indicated in Table 1 and Figure 5 respectively. Conversely, this observation revealed that population density is proportional to environmental impact. And as such, the awareness of incorporating environmental impact monitors such as $\mathrm{CO}_{2}$ and GHGs monitors in urban centre (OCAEZ) is higher than the less dwelling places.

\section{Conclusion}

The aim of this study is to determine the sustainable indicators that could be evaluated in housing design project. Sustainable building is a measure to safeguard and shielding the environment from the building industrial sector. Generally, there is a growing awareness on the incorporation of sustainable housing indicator such as environmental impact indicator, energy and air quality control on the housing design in Ondo State with particular emphasis in Ondo Central District (OCAEZ). Holistic implementation of sustainable indicator (SHI) in Ondo State will be useful for economic integration and development. Findings have showed that there is significant relationship among SHI, socio-economic and environmental performance. In order to achieve a sustainable building 
structure and reduce the construction cost and negative effect of building construction, all the sustainable housing indicator should be well designed and incorporated into the building.

\section{References}

[1] P. O. Akadiri, A. Ezekiel, A. Chinyio, and P. O. O., "Design of a sustainable building: A conceptual framework for implementing sustainability in the building sector," Buildings, vol. 2, pp. 126-152, 2012. Available at: https://doi.org/10.3390/buildings2020126.

[2] S. Yılmaz, "Sustainable design in architecture," presented at the A International Design Conference Design 2006 Dubrovnik Croatia, May 15 - 18, 2006, 2006

[3] O. Ortiz, F. Castells, and G. Sonnemann, "Sustainability in the construction industry: A review of recent developments based on LCA," Construction and Building Materials, vol. 23, pp. 28-39, 2009. Available at: https://doi.org/10.1016/j.conbuildmat.2007.11.012.

[4] G. John, D. Clements-Croome, and G. Jeronimidis, "Sustainable building solutions: A review of lessons from the natural world," Building and Environment, vol. 40, pp. 319-328, 2005. Available at: https://doi.org/10.1016/j.buildenv.2004.05.011.

[5] L. Bragança, M. V. Susana, and B. A. Joana, "Early stage design decisions: The way to achieve sustainable buildings at lower costs," 2014.

[6] M. Asif, T. Muneer, and R. Kelley, "Life cycle assessment: A case study of a dwelling home in Scotland," Building and Environment, vol. 42, pp. 1391-1394, 2007. Available at: https://doi.org/10.1016/j.buildenv.2005.11.023.

[7] ODSMA, "Categorization of agro-ecological zones in Ondo State," Bulletin, vol. 5, p. 65, 2007.

[8] N. Bruce, R. Perez-Padilla, and R. Albalak, "Indoor air pollution in developing countries: A major environmental and public health challenge," Bulletin of the World Health Organization, vol. 78, pp. 1078-1092, 2000.

[9] E. Duflo, M. Greenstone, and R. Hanna, "Indoor air pollution, health and economic well-being," SAPI EN. S. Surveys and Perspectives Integrating Environment and Society, vol. 3, pp. 70-75, 2008.

[10] U. Bogenstätter, "Prediction and optimization of life-cycle costs in early design," Building Research छ Information, vol. 28, pp. 376386, 2000. Available at: https://doi.org/10.1080/096132100418528.

[11] G. Pellegrini-Masini, G. Bowles, A. D. Peacock, M. Ahadzi, and P. F. Banfill, "Whole life costing of domestic energy demand reduction technologies: Householder perspectives," Construction Management and Economics, vol. 28, pp. 217-229, 2010. Available at: https://doi.org/10.1080/01446190903480027.

[12] D. G. Woodward, "Life cycle costing-theory, information acquisition and application," International Journal of Project Management, vol. 15, pp. 335-344, 1997.

[13] M. Lenzen and G. Treloar, "Embodied energy in buildings: wood versus concrete—reply to Börjesson and Gustavsson," Energy Policy, vol. 30, pp. 249-255, 2002. Available at: https://doi.org/10.1016/s0301-42 15(01)00142-2. 